\title{
Effects of Intraduodenal Infusions of L-phenylalanine and L-glutamine on Antropyloroduodenal Motility and Plasma Cholecystokinin in Healthy Men
}

\author{
Robert E Steinert, ${ }^{1 *}$ Maria F Landrock, ${ }^{1}$ Michael Horowitz, ${ }^{1,2}$ and Christine Feinle-Bisset ${ }^{1,2}$ \\ ${ }^{1}$ Discipline of Medicine, The University of Adelaide, Royal Adelaide Hospital, Adelaide, Australia; and ${ }^{2}$ NHMRC Center of Research Excellence \\ in Translating Nutritional Science to Good Health, Adelaide, Australia
}

\begin{abstract}
Background/Aims
Dietary proteins have potent eating-inhibitory and glucose-lowering effects, which may be mediated via effects of amino acids on gastrointestinal hormone and motor function, although little information is available. We have now evaluated the effects of L-phenylalanine (L-Phe) and L-glutamine (L-GIn) on antropyloroduodenal motility and plasma cholecystokinin (CCK) concentrations.
\end{abstract}

\section{Methods}

Two double-blind, 3-way cross-over studies were performed, each including 10 healthy, normal-weight men. We determined the antropyloroduodenal motor and plasma CCK responses to 90-minute intraduodenal infusions of L-Phe (study A) or L-Gln (study B), each at $0.15 \mathrm{kcal} / \mathrm{min}$ (total $13.5 \mathrm{kcal}$ ), or $0.45 \mathrm{kcal} / \mathrm{min}$ (total $40.5 \mathrm{kcal})$, or saline (control), in randomized fashion.

Results

Intraduodenal L-Phe at $0.45 \mathrm{kcal} / \mathrm{min}$, but not at $0.15 \mathrm{kcal} / \mathrm{min}$, suppressed antral $(P<0.01)$, and stimulated phasic $(P<$ $0.01)$, but not tonic, pyloric, or duodenal pressures, while L-Phe at both $0.15 \mathrm{kcal} / \mathrm{min}$ and $0.45 \mathrm{kcal} / \mathrm{min}$ stimulated plasma CCK. In contrast, L-Gln had no effect on antral, duodenal or pyloric pressures, or plasma CCK.

\section{Conclusions}

Intraduodenal infusions of L-Phe and L-Gln, in doses of $0.15 \mathrm{kcal} / \mathrm{min}$ and $0.45 \mathrm{kcal} / \mathrm{min}$ for 90 minutes, have different effects

Received: November 30, 2014 Revised: January 5, 2015 Accepted: January 6, 2015

(c) This is an Open Access article distributed under the terms of the Creative Commons Attribution Non-Commercial License (http://creativecommons.

org/licenses/by-nc/4.0) which permits unrestricted non-commercial use, distribution, and reproduction in any medium, provided the original work is properly cited.

*Correspondence: Robert E Steinert, PhD

Discipline of Medicine, The University of Adelaide, Royal Adelaide Hospital, Adelaide 5005, Australia

Tel: +61-8-8222-5247, Fax: +61-8-8223-3870, E-mail: re.steinert@gmail.com

Financial support: This study was supported by National Health and Medical Research Council of Australia (NHMRC) Senior Research Fellowship (Grant No. 627002, 2010-2015), a Mary Overton Early Career Fellowship 2012-2014, Royal Adelaide Hospital Research Committee project grant (2013), and a Diabetes Australia Research Trust grant (2014).

Conflicts of interest: None.

Author contributions: Robert E Steinert contributed to study concepts and design, study coordination and performance, data and statistical analysis, data interpretation, and drafting of the manuscript; Maria F Landrock contributed to study coordination and performance, subject recruitment, and data analysis; Michael Horowitz contributed to study concepts and design, data interpretation, and drafting of the manuscript; and Christine Feinle-Bisset contributed to study concept and design, data analysis and interpretation, and drafting of the manuscript. Christine Feinle-Bisset takes final responsibility for the manuscript content. All authors have approved the final version of the manuscript.

Clinical trial registry: The study was registered as a clinical trial with the Australia and New Zealand Clinical Trial Registry (www.anzctr.org.au; ACTRN12612000846820, ACTRN12612000826842).

ORCID: Robert E Steinert, http://orcid.org/0000-0001-7884-5036l; Maria F Landrock, http://orcid.org/0000-0002-3498-3274; Michael Horowitz, http://orcid.org/0000-0002-3067-7157; Christine Feinle-Bisset, http://orcid.org/0000-0001-6848-0125. 
on antropyloroduodenal motility and CCK in normal-weight men. The modulation of antral and pyloric pressures and CCK may contribute to the eating-inhibitory effects of oral L-Phe, possibly through the slowing of gastric emptying.

(J Neurogastroenterol Motil 2015;21:404-413)

\section{Key Words}

Amino acids; Eating; Gastrointestinal hormones; Gastrointestinal motility; Humans

\section{Introduction}

It is increasingly recognised that the effects of protein on upper gastrointestinal (GI) motor and hormone function contribute to the effects of dietary protein to diminish energy intake and improve postprandial glycaemic control. ${ }^{1-5}$ For example, we recently found that acute ingestion of $55 \mathrm{~g}$ whey protein prior to a mashed-potato meal slowed gastric emptying, stimulated insulin, and reduced postprandial blood glucose in type 2 diabetic patients. Furthermore, high-protein meals, when compared with isocaloric meals high in fat or carbohydrate, reduced energy intake, in both lean and obese subjects, and this was associated with a sustained stimulation of plasma cholecystokinin (CCK). ${ }^{2}$

It is well established that CCK modulates upper gut functions, including antropyloroduodenal (APD) motility, gastric emptying, and pancreatic secretion. ${ }^{6-9}$ For example, exogenous administration of CCK stimulates tonic and phasic pyloric pressures in healthy men, ${ }^{6}$ and loxiglumide, a CCK receptor antagonist, markedly accelerates gastric emptying of both solids and liquids in healthy volunteers. ${ }^{8}$

The release of fatty acids from triglycerides during digestion is critical for the effects of fat on upper GI motility, gastric emptying, and gut hormone release, ${ }^{10-14}$ and it appears that digestion of protein to amino acids is a similar prerequisite. ${ }^{15}$ A number of amino acids have been reported to affect APD motility and gut hormone secretion. For example, intraduodenal (ID) L-tryptophan (L-Trp) stimulates pyloric pressures, ${ }^{16,17}$ as well as the secretion of gut hormones, including $\mathrm{CCK},{ }^{16}$ at loads as low as 0.15 $\mathrm{kcal} / \mathrm{min}$ given for 90 minutes to healthy lean men. L-phenylalanine (L-Phe) and L-glutamine (L-Gln) have also been reported to affect aspects of gut motor and hormone functions. For example, L-Phe, when administered orally in amounts of up to 10 g, potently increased plasma CCK in humans, ${ }^{18}$ while L-Gln, administered ID at a load amounting to $15 \mathrm{~g}$ and in the presence of glucose, stimulated pyloric pressures in healthy subjects and type 2 diabetic patients. ${ }^{19}$
The effects of L-Phe and L-Gln on APD motility, particularly the activity of the pylorus, which is the major determinant of the slowing of gastric emptying, and the relationship with the magnitude of the stimulation of CCK, have not been investigated comprehensively. We hypothesized that increasing ID loads of L-Phe and L-Gln would potently affect both, APD motility and plasma CCK concentrations.

\section{Materials and Methods}

\section{Subjects}

Two double-blind, 3-way crossover studies were performed, each in 10 healthy, normal-weight men (study A: mean age 23.6 \pm 2.0 years [range 18-40], body mass index [BMI] $22.5 \pm 0.6$ $\mathrm{kg} / \mathrm{m}^{2}$ [range 19.4-25.0]; study B: mean age $27.2 \pm 3.9$ years [range 18-48], BMI $22.5 \pm 0.7 \mathrm{~kg} / \mathrm{m}^{2}$ [range 18.5-25.3]) (Fig. 1). Exclusion criteria were smoking, consumption of $>20 \mathrm{~g}$ of alcohol/day, any medical condition, GI symptoms, and the use of medications known to affect GI function. The study protocol was approved by the Royal Adelaide Hospital Research Ethics Committee and carried out in accordance with the Declaration of Helsinki. Each subject provided informed written consent prior to their enrolment.

\section{Study Design and Protocol}

Subjects were studied on three occasions each, separated by 3-10 days, on which they received, in randomized, double-blind fashion, 90-minute ID infusions of either L-Phe at (i) 0.15 $\mathrm{kcal} / \mathrm{min}$ ("L-Phe 0.15 "), or (ii) $0.45 \mathrm{kcal} / \mathrm{min}$ ("L-Phe 0.45 "), or (iii) control (study A); or L-Gln at (i) $0.15 \mathrm{kcal} / \mathrm{min}$ ("L-Gln 0.15 "), or (ii) $0.45 \mathrm{kcal} / \mathrm{min}$ ("L-Gln 0.45 "), or (iii) control (study B). The lower load was chosen based on the dose of L-Trp shown to be effective in stimulating plasma CCK and pyloric pressures in our previous study ${ }^{16}$ while the higher load equated to the load of $10 \mathrm{~g}$ of L-Phe, which was reported to stimulate plasma $\mathrm{CCK}{ }^{18}$ Amino acid solutions were prepared by dissolving (i) 3.3 


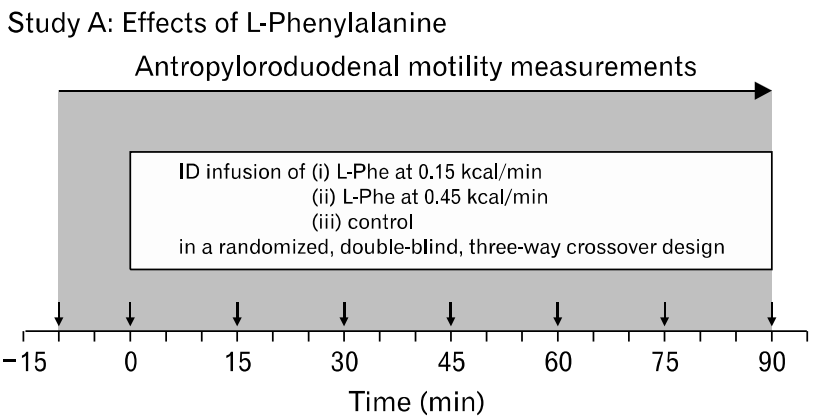

Study B: Effects of L-Glutamine

Antropyloroduodenal motility measurements

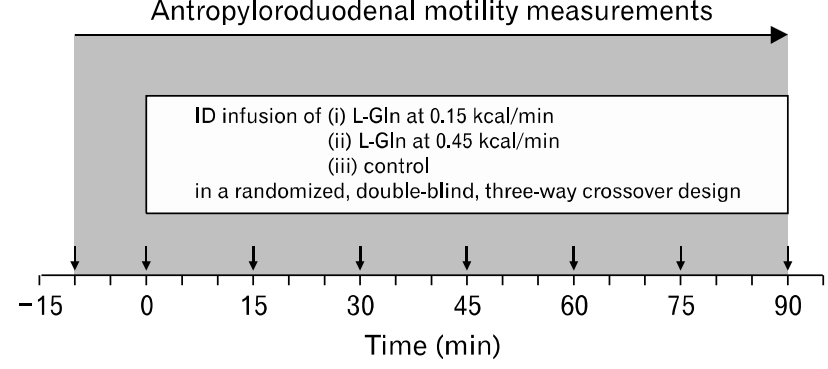

Figure 1. Experimental design of studies A and B each including 10 healthy, normal-weight men. Subjects were studied on three occasions on which they received, in randomized, double-blind fashion, a 90-minute intraduodenal (ID) infusion of either L-phenylalanine (L-Phe) at (i) $0.15 \mathrm{kcal} / \mathrm{min}$, or (ii) $0.45 \mathrm{kcal} / \mathrm{min}$, or (iii) control (study A); or L-glutamine (L-Gln) at (i) $0.15 \mathrm{kcal} / \mathrm{min}$, or (ii) $0.45 \mathrm{kcal} / \mathrm{min}$, or (iii) control (study B). Antropyloroduodenal motility was recorded continuously and blood samples were collected for measurements of plasma cholecystokinin at regular time intervals from $\mathrm{t}=-10$ minutes until $\mathrm{t}=90$ minutes.

g, or (ii) 9.9 g crystalline L-Phe or L-Gln (PureBulk, Roseburg, OR, USA), $118.3 \mathrm{mg} \mathrm{CaCl} 2 \times 2 \mathrm{H}_{2} \mathrm{O}$ and $\mathrm{NaCl}$ (3.8 $\mathrm{g}$ and $2.3 \mathrm{~g}$ in study $\mathrm{A}$, and $3.6 \mathrm{~g}$ and $2.1 \mathrm{~g}$ in study $\mathrm{B}$, respectively, to achieve isotonic (300 mosm) solution) in $405 \mathrm{~mL}$ distilled water. The isotonic control solution contained $118.3 \mathrm{mg} \mathrm{CaCl} \times 2 \mathrm{H}_{2} \mathrm{O}$ and $4.6 \mathrm{~g} \mathrm{NaCl}$ in $405 \mathrm{~mL}$ distilled water. All solutions were administered at a rate of $4.5 \mathrm{ml} / \mathrm{min}$. A research officer, who was not otherwise involved in the performance of the studies or data analysis, prepared the solutions.

Subjects were instructed to abstain from alcohol and strenuous exercise for 24 hours, and provided with a standardized meal (Beef Lasagne, McCain Food, Wendouree, Victoria, Australia; total energy content: $1160 \mathrm{kcal}$ ) to be consumed at 19:00 the night before each visit. Subjects then fasted overnight from any further solids and liquids, except water, until they attended the laboratory at 08:30 the following day. On arrival, a small-diameter (3.5 mm), 17-channel manometric catheter (total length: $100 \mathrm{~cm}$; Dentsleeve International, Mui Scientific, Mississauga, Ontario, Canada) was inserted into the stomach through an anaesthetized nostril and allowed to pass into the duodenum by peristalsis. The catheter contained 16 side-holes, spaced at 1.5 $\mathrm{cm}$ intervals, to measure pressures in the APD region. Six side-holes (channels 1-6) were positioned in the antrum, a $4.5 \mathrm{~cm}$ sleeve-sensor (channel 7) with 2 channels (channels 8 and 9) on the back of the sleeve was positioned across the pylorus, and 7 channels (channels 10-16) were positioned in the duodenum. The correct positioning of the catheter, with the sleeve sensor straddling the pylorus, was maintained by continuous measurement of the transmucosal potential difference between the most distal antral channel (channel 6: approximately $-20 \mathrm{mV}$ ) and the most proximal duodenal channel (channel 10: approximately $+10 \mathrm{mV}) .^{20}$ The manometric channels were perfused with degassed, distilled water, except for the transmucosal potential difference channels, which were perfused with degassed $0.9 \%$ saline, at $0.15 \mathrm{~mL} / \mathrm{min}$. An additional channel, used for ID infusion of amino acid and control solutions, was located $14.5 \mathrm{~cm}$ distal to the pylorus.

Once the catheter was positioned correctly, fasting motility was observed until the occurrence of phase III of the interdigestive migrating motor complex. Immediately after the end of phase III, during motor quiescence (ie, phase I of the migrating motor complex), an intravenous cannula was placed in a forearm vein for blood sampling with baseline blood sample $(t=-10$ minutes) taken and baseline motility recording obtained $(\mathrm{t}=$ $-10-0$ minutes). At $t=0$ minute, another blood sample was taken and ID infusions of amino acids or control (study A: L-Phe, study B: L-Gln), commenced and were continued for 90 minutes (ie, from $t=0-90$ minutes). APD motility was recorded continuously and blood samples for measurements of plasma CCK were collected at every 15 minuts. At $t=90$ minutes, the infusion was terminated and the manometric catheter and the intravenous cannula removed, and the subject was allowed to leave the laboratory.

\section{Measurements}

Blood samples were collected into ice-chilled ethylenediaminetetraacetic acid (EDTA) tubes. Plasma was then separated by centrifugation at $3200 \mathrm{rpm}$ for 15 minutes at $4^{\circ} \mathrm{C}$ within 15 minutes of collection and stored at $-70^{\circ} \mathrm{C}$ until assayed. Plasma CCK-8 (pmol/L) was measured by radioimmunoassay after ethanol extraction using an adaptation of the method of Santangelo et 
al. ${ }^{21}$ Standards were prepared using synthetic sulfated CCK-8 (Sigma Chemical, St Louis, MO, USA) and an anti CCK-8 antibody (C2581, Lot 105H4852; Sigma Chemical). This antibody binds all CCK peptides containing the sulfated tyrosine residue in position 7 , showing a $26 \%$ cross-reactivity with unsulfated CCK-8, less than $2 \%$ cross-reactivity with human gastrin I, and does not bind to structurally unrelated peptides. Sulfated CCK-8 ${ }^{125}$ I-labeled with Bolton and Hunter reagent (Perkin Elmer, Boston, MA, USA) was used as tracer, and samples were incubated for 7 days at $4^{\circ} \mathrm{C}$. The antibody-bound fraction was separated by the addition of dextran-coated charcoal containing gelatin and the radioactivity determined in the supernatants following centrifugation. Intra- and inter-assay coefficients of variation were $8.3 \%$ and $12.6 \%$, respectively. The detection limit was 1 $\mathrm{pmol} / \mathrm{L}$.

APD motility was recorded and digitized using a computerbased system that ran commercially available software (Solar GI, Medical Measurement Systems Database software version 8.17, Medical Measurement Systems, Enschede, The Netherlands). Data were analysed for (1) the number and amplitude of antral and duodenal pressure waves (PWs), (2) the number and amplitude of isolated pyloric pressure waves (IPPWs), and (3) basal pyloric pressure (BPP), using custom-written software modified to our requirements (Prof. André Smout, Department of Gastroenterology, Academic Medical Center, Amsterdam, Netherlands). Phasic PWs were defined by an amplitude $>10 \mathrm{mmHg}$ with a minimum time interval of 15 seconds between peaks for antral and pyloric waves and 3 seconds for duodenal waves. ${ }^{22,23} \mathrm{BPP}$ was calculated by subtracting the mean basal pressure (with phasic pressures excluded) recorded at the most distal antral channel from the mean basal pressure recorded at the sleeve. ${ }^{20}$

\section{Data Analysis and Statistical Methods}

The number of subjects was determined by power calculations based on our previous study with ID L-Trp. ${ }^{16}$ We calculated that with 10 subjects we would be able to detect a significant difference in the maximum number of isolated pyloric pressure waves per 15 minutes of 15 at $\alpha=0.05$, with a power of $80 \%$, within groups.

Baseline values for antral, duodenal and pyloric pressures as well as plasma CCK were calculated as means of values obtained between $\mathrm{t}=-10$ to $\mathrm{t}=0$ minute. During infusions, the number and amplitude of IPPWs and BPP were expressed as mean values over 15-minute periods. The number and amplitude of antral and duodenal PWs were used to calculate antral and duodenal motility indices $(\mathrm{MI})$, using the equation: $\mathrm{MI}(\mathrm{mmHg} \times$ number $)=\ln [$ (sum of amplitudes x number of phasic PWs $)]+1 .^{24}$ The number, amplitude, and MI of antral and duodenal PWs were expressed as mean values over the entire 90-minute infusion period.

Statistical analysis was performed using SPSS software (version 19.0, SPSS, Chicago, IL). BPP, IPPWs, and plasma $\mathrm{CCK}$ were analyzed by repeated-measures two-factor analysis of variance (ANOVA), with time (0-90 minutes) and treatment (L-Phe 0.15, L-Phe 0.45, control, or L-Gln 0.15, L-Gln 0.45, control) as factors. The number, amplitude and MI of antral and duodenal PWs were analyzed by one-factor ANOVA. Post-hoc comparisons, adjusted for multiple comparisons by Bonferroni's correction, were performed, where ANOVAs revealed significant effects, between either dose of amino acid versus control, as the primary focus of this study. Correlations among area under the curves (AUCs, calculated by using the trapezoidal rule) for CCK with AUC for IPPWs and BPP and with antral and duodenal pressures, as well as with the amino acid load, were assessed using linear within-subject correlation analysis corrected for repeated measures. ${ }^{25}$ To assess differences in effects between the two amino acids, we compared the above parameters, corrected for values obtained during control, at the load of $0.45 \mathrm{kcal} / \mathrm{min}$, using unpaired $t$ tests. $\mathrm{R}$ values $>0.5$ were considered physiologically relevant. All data are reported as means \pm SEM. All tests were two-tailed, and differences were considered statistically significant at $P<0.05$.

\section{Results}

In both studies, all subjects completed all 3 study visits, and the study conditions were well tolerated, with no subject experiencing adverse effects. All data are from all subjects $(\mathrm{n}=10)$, with the exception of basal pyloric pressures in study A (L-Phe), for which data analysis was not possible in 2 subjects, due to technical problems.

\section{Study A: Effects of L-phenylalanine}

\section{Antropyloroduodenal pressures}

Baseline values for antral, duodenal and pyloric pressures did not differ among study days (data not shown).

Antral pressures. There was an effect of treatment on the mean amplitude $(P<0.01)$ and the MI $(P<0.01)$, but not the total number, of antral PWs (Table 1). L-Phe 0.45 and L-Phe 
Table 1. Effects of Intraduodenal Infusions of L-Phenylalanine (Study A) or L-Glutamine (Study B), Each at Loads of $0.15 \mathrm{kcal} / \mathrm{min}$ or 0.45 $\mathrm{kcal} / \mathrm{min}$, or Saline Control, Each for 90 Minutes at a Rate of $4 \mathrm{~mL} / \mathrm{min}$, on Antral and Duodenal Pressures

\begin{tabular}{|c|c|c|c|c|}
\hline & Control & $0.15 \mathrm{kcal} / \mathrm{min}$ & $0.45 \mathrm{kcal} / \mathrm{min}$ & $P$-value \\
\hline \multicolumn{5}{|l|}{ L-phenylalanine } \\
\hline \multicolumn{5}{|l|}{ Antral pressures } \\
\hline Number & $76 \pm 12$ & $60 \pm 12$ & $38 \pm 12$ & NS \\
\hline Amplitude (mmHg) & $60 \pm 10$ & $31 \pm 5^{\mathrm{a}}$ & $22 \pm 4^{a}$ & $<0.001$ \\
\hline MI (mmHg) & $12 \pm 1$ & $11 \pm 1$ & $9 \pm 1^{a}$ & $<0.01$ \\
\hline \multicolumn{5}{|l|}{ Duodenal pressures } \\
\hline Number & $466 \pm 55$ & $443 \pm 52$ & $490 \pm 55$ & NS \\
\hline Amplitude (mmHg) & $27 \pm 1$ & $30 \pm 3$ & $28 \pm 2$ & NS \\
\hline $\mathrm{MI}(\mathrm{mmHg})$ & $16 \pm 0$ & $16 \pm 0$ & $16 \pm 0$ & NS \\
\hline \multicolumn{5}{|l|}{ L-glutamine } \\
\hline \multicolumn{5}{|l|}{ Antral pressures } \\
\hline Number & $97 \pm 20$ & $90 \pm 18$ & $70 \pm 11$ & NS \\
\hline Amplitude (mmHg) & $50 \pm 7$ & $43 \pm 8$ & $29 \pm 4$ & NS \\
\hline MI (mmHg) & $13 \pm 1$ & $12 \pm 1$ & $12 \pm 0$ & NS \\
\hline \multicolumn{5}{|l|}{ Duodenal pressures } \\
\hline Number & $609 \pm 110$ & $620 \pm 73$ & $522 \pm 62$ & NS \\
\hline Amplitude (mmHg) & $24 \pm 1$ & $25 \pm 2$ & $24 \pm 2$ & NS \\
\hline $\mathrm{MI}(\mathrm{mmHg})$ & $16 \pm 0$ & $16 \pm 0$ & $16 \pm 0$ & NS \\
\hline
\end{tabular}

MI, motility index, NS, not significant.

${ }^{\mathrm{a}} P<0.05$ vs control. Data are means \pm SEM $(\mathrm{n}=10)$ healthy mean in each of study.

0.15 reduced the amplitude, and L-Phe 0.45 , but not L-Phe 0.15, reduced the MI, of antral PWs compared with control.

Basal pyloric pressure. There was no effect of treatment on BPP (Fig. 2A).

Isolated pyloric pressure. There was an effect of treatment on the number $(P<0.05)$ (Fig. 2B), but not the amplitude (Fig. 2C), of IPPWs. The mean number of IPPWs was higher during L-Phe 0.45, but not L-Phe 0.15, compared with control, however, post-hoc comparisons revealed no significant differences between treatments.

Duodenal pressures. There was no effect of treatment on the total number, mean amplitude, or the MI, of duodenal PWs (Table 1).

\section{Plasma cholecystokinin concentrations}

Baseline plasma concentrations did not differ among study days. There was a treatment $\times$ time interaction $(P<0.05)$ for plasma CCK (Fig. 3A). L-Phe 0.45 increased plasma CCK promptly at 15 minutes, and the effect was sustained until $t=90$ minutes compared with control. L-Phe 0.15 increased plasma $\mathrm{CCK}$ at $15-30$ minutes and at 60 minutes and 90 minutes compared with control.
Correlations between the load of L-phenylalanine, antropyloroduodenal motility, and plasma cholecystokinin

There was a negative correlation between the dose of L-Phe and the total number $(r=-0.50, P<0.05)$, mean amplitude $(\mathrm{r}$ $=-0.67, P<0.001)$ and $\mathrm{MI}(r=-0.63, P<0.05)$ of antral PWs, and a positive correlation between the dose of L-Phe and the AUC for the number of IPPWs $(r=0.52, P<0.05)$ and the AUC for plasma CCK $(r=0.71, P<0.001)$. In addition, the AUC for plasma CCK was inversely related to the mean amplitude of antral PWs $(r=-0.65, P=0.001)$.

\section{Study B: Effects of L-glutamine}

\section{Antropyloroduodenal pressures}

Baseline values for antral, duodenal and pyloric pressures did not differ among study days (data not shown).

Antral pressures. There was no effect of treatment on the total number, mean amplitude, or the MI, of antral PWs (Table 1).

Basal pyloric pressure. There was no effect of treatment on BPP (Fig. 2D).

Isolated pyloric pressure. There was no effect of treatment 
A

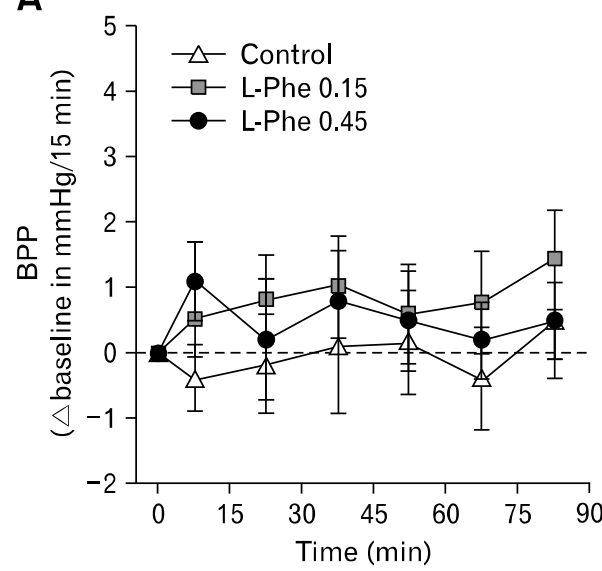

B

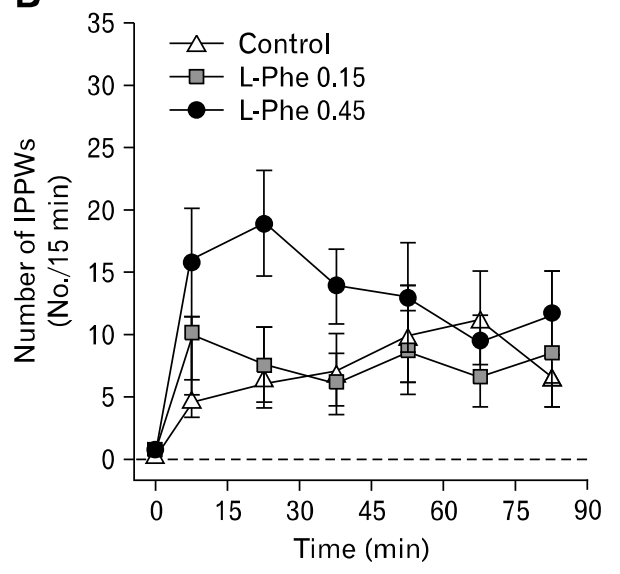

C

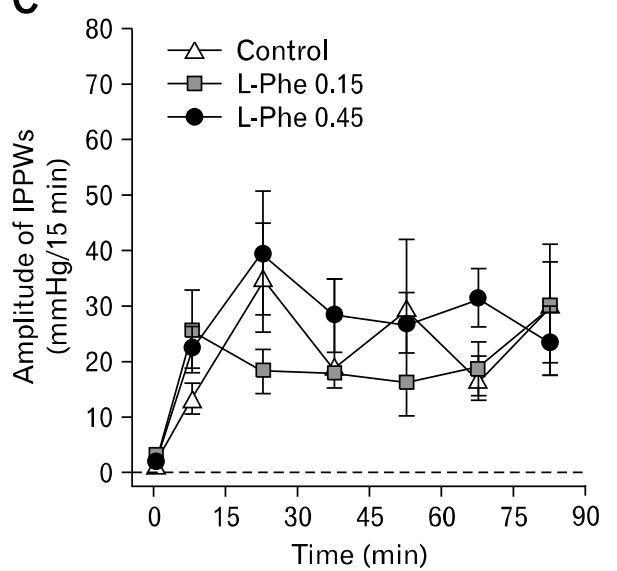

D

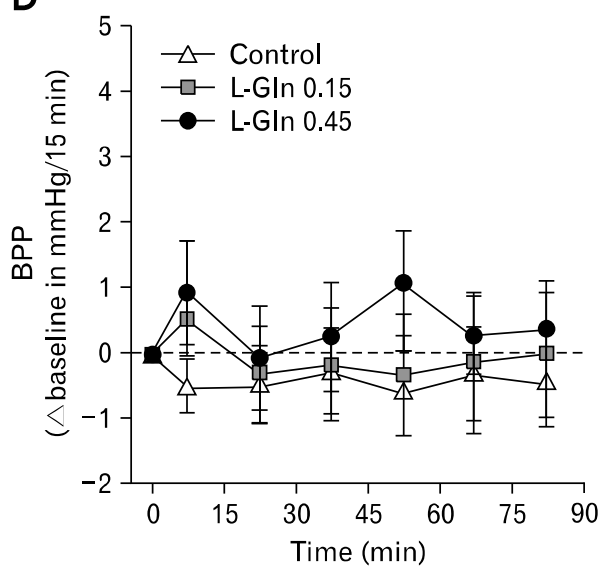

E

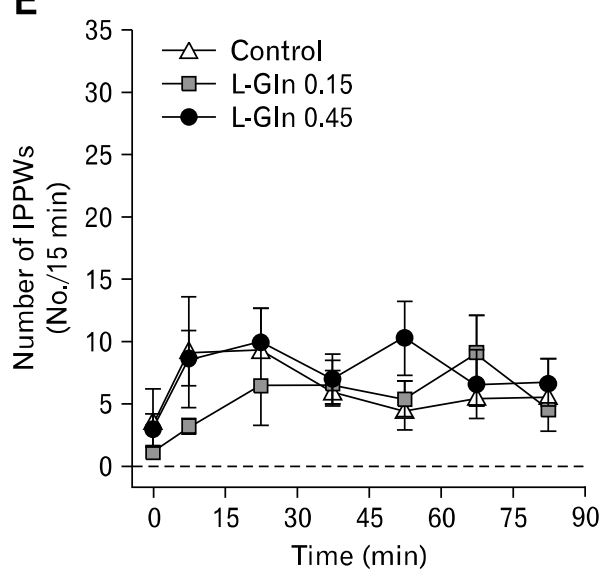

F

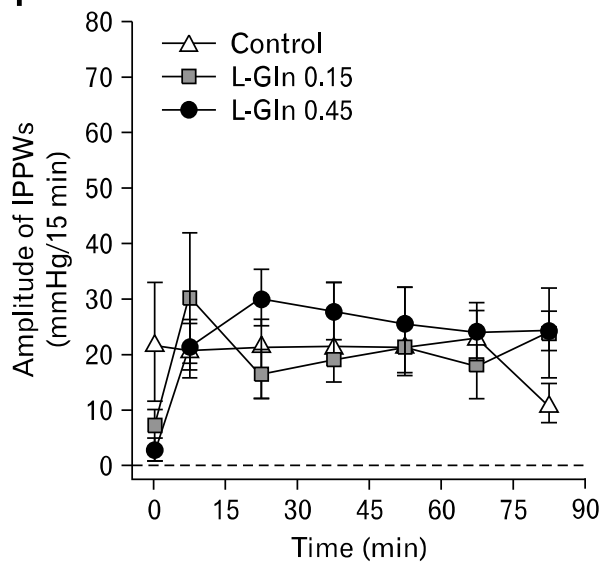

Figure 2. Basal pyloric pressure (BPP) $(\mathrm{A}, \mathrm{D})$, and number $(\mathrm{B}, \mathrm{E})$, and amplitude $(\mathrm{C}, \mathrm{F})$ of isolated pyloric pressure waves (IPPWs) during 90minute intraduodenal (ID) infusions of L-phenylalanine (L-Phe; A, B, C), or L-glutamine (L-Gln; D, E, F), at (1) $0.15 \mathrm{kcal} / \mathrm{min}$ (L-Phe 0.15 or L-Gln 0.15 ), or (2) $0.45 \mathrm{kcal} / \mathrm{min}$ (L-Phe 0.45 ) or (L-Gln 0.45), or saline control. Repeated-measures analyses of variance, with treatment and time as factors, were used to assess differences in BPP and IPPWs. Post-hoc comparisons, adjusted for multiple comparisons by Bonferroni's correction, were used to determine significant differences between either dose and control. B: Treatment effect $(P<0.05)$. Data are means $\pm \mathrm{SE}(\mathrm{n}=10)$, except for study A $(\mathrm{n}=8)$. on the number (Fig. 2E), or amplitude (Fig. 2F), of IPPWs.

Duodenal pressures. There was no effect of treatment on the total number, mean amplitude, or the MI, of duodenal PWs (Table 1).

\section{Plasma cholecystokinin concentrations}

Baseline plasma concentrations did not differ among study days. There was no effect of L-Gln on plasma CCK concentrations (Fig. 3B). 
A

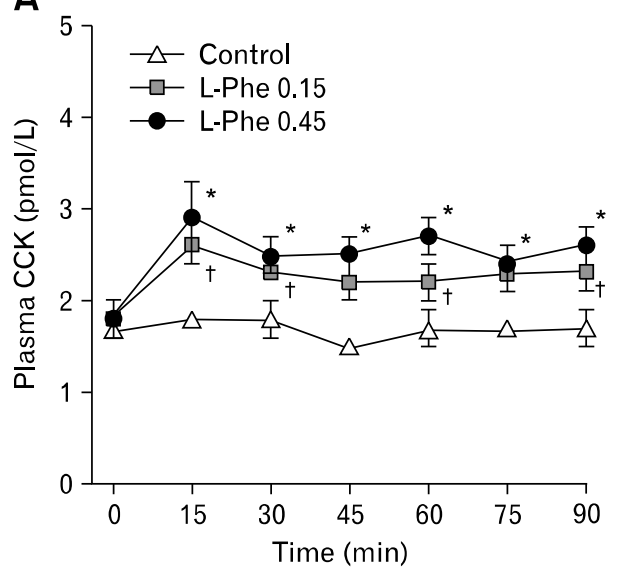

B

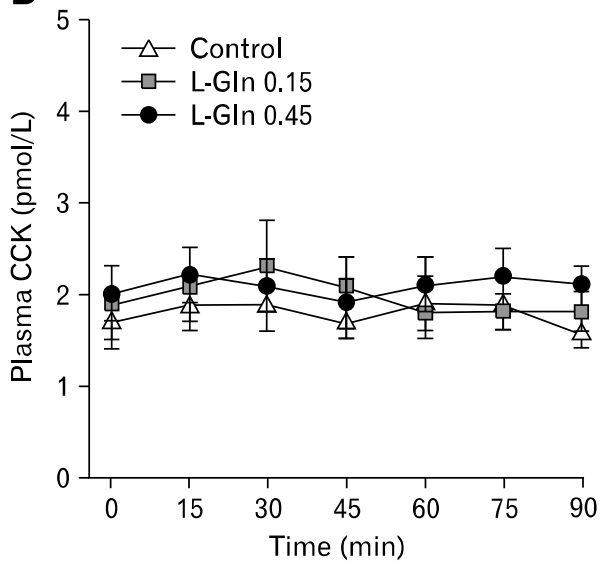

Figure 3. Plasma cholecystokinin (CCK) during 90-minute intraduodenal (ID) infusions of L-phenylalanine (L-Phe; A), or L-glutamine (L-Gln; B), at (1) $0.15 \mathrm{kcal} / \mathrm{min}$ (L-Phe 0.15 or L-Gln 0.15), or (2) $0.45 \mathrm{kcal} / \mathrm{min}$ (L-Phe 0.45 or L-Gln 0.45 ), or saline control. Repeated-measures analyses of variance, with treatment and time as factors, were used to assess differences in cholecystokinin. Post-hoc comparisons, adjusted for multiple comparisons by Bonferroni's correction, were used to determine significant differences between either dose and control. A: Treatment $\times$ time interaction $(P<0.05) ;{ }^{*} \mathrm{~L}-\mathrm{Phe} 0.45$ vs control, ${ }^{\dagger} \mathrm{L}-\mathrm{Phe} 0.15$ vs control. Data are means $\pm \mathrm{SE}(\mathrm{n}=10)$.

Table 2. Comparative Effects of Intraduodenal Infusions of L-Phenylalanine (Study A) or L-Glutamine (Study B), at $0.45 \mathrm{kcal} / \mathrm{min}$, for $90 \mathrm{Minutes}$ at a Rate of $4 \mathrm{~mL} / \mathrm{min}$, on Antropyloroduodenal Motility and Cholecystokinin Secretion

\begin{tabular}{|c|c|c|c|}
\hline & L-Phenylalanine & L-Glutamine & $P$-value \\
\hline \multicolumn{4}{|c|}{ Antral pressures (change from control) } \\
\hline Number & $-38 \pm 16$ & $-28 \pm 20$ & NS \\
\hline Amplitude (mmHg) & $-38 \pm 11$ & $-20 \pm 9$ & NS \\
\hline $\mathrm{MI}(\mathrm{mmHg})$ & $-2.8 \pm 0.9$ & $-1.3 \pm 0.6$ & NS \\
\hline \multicolumn{4}{|c|}{ Duodenal pressures (change from control) } \\
\hline Number & $24 \pm 77$ & $-87 \pm 142$ & NS \\
\hline Amplitude (mmHg) & $1 \pm 1$ & $1 \pm 2$ & NS \\
\hline $\mathrm{MI}(\mathrm{mmHg})$ & $0.1 \pm 0.3$ & $-0.2 \pm 0.4$ & NS \\
\hline \multicolumn{4}{|c|}{ Basal pyloric pressures (change from control) } \\
\hline AUC & $50 \pm 70$ & $74 \pm 55$ & NS \\
\hline \multicolumn{4}{|c|}{ Isolated pyloric pressure waves (change from control) } \\
\hline AUC Number & $513 \pm 213$ & $119 \pm 148$ & NS \\
\hline AUC Amplitude (mmHg) & $487 \pm 209$ & $227 \pm 235$ & NS \\
\hline \multicolumn{4}{|l|}{ CCK (change from control) } \\
\hline AUC & $74.6 \pm 13.9$ & $26.9 \pm 16.6$ & $<0.05$ \\
\hline
\end{tabular}

MI, motility index; AUC, area under the curve; CCK, cholecystokinin.

Data are means $\pm \operatorname{SEM}(\mathrm{n}=10$, except for basal pyloric pressure in study $A[n=8])$.

\section{Correlations between the load of L-glutamine, antropyloroduodenal motility, and plasma cholecystokinin}

There were no correlations between antral, pyloric or duodenal pressures, or plasma CCK, and the load of L-Gln administered, or between the AUC for plasma CCK and antral, duodenal or pyloric pressures.

\section{Comparative effects between L-phenylalanine and L-glutamine}

There were no significant differences in antral, tonic or phasic pyloric, or duodenal pressures, between L-Phe and L-Gln administered at $0.45 \mathrm{kcal} / \mathrm{min}$, although mean values for tonic and phasic pyloric pressures were markedly higher during L-Phe than L-Gln (Table 2). Plasma CCK concentrations were greater 
during L-Phe, when compared with L-Gln $(P<0.05)$.

\section{Discussion}

We have investigated the effects of acute ID administration of two amino acids, L-Phe and L-Gln, on APD motility and plasma CCK in healthy men. We found that while L-Phe suppressed antral pressure, stimulated phasic pyloric pressure, and increased plasma CCK, in a dose-dependent manner, there was no effect of L-Gln in identical dosage on these outcomes. These observations, accordingly, establish that the effects of amino acids on upper GI function are distinct.

The findings relating to the effect of L-Phe on plasma CCK are consistent with earlier reports; Ballinger and Clark ${ }^{18}$ found that in healthy men $10 \mathrm{~g}$ of orally administered L-Phe increased plasma CCK about 5 -fold within 20 minutes. Our data show that when infused directly into the small intestine at a constant rate of $0.45 \mathrm{kcal} / \mathrm{min}$ over 90 minutes (totalling $9.9 \mathrm{~g}$ ), L-Phe also stimulates the release of CCK. However, there were 2 major differences: (1) while plasma CCK peaked within 15 minutes, the increase was only about 1.5 -fold, which is much less than reported previously, ${ }^{18}$ but comparable to that observed in our recently published study with $3.3 \mathrm{~g}(0.15 \mathrm{kcal} / \mathrm{min})$ of L-Trp, also infused over 90 minutes, ${ }^{16}$ and (2) in contrast to orally administered $\mathrm{L}_{-} \mathrm{Phe}^{18}$ we found that in response to ID L-Phe, plasma CCK concentrations remained elevated over the 90-minute infusion period. One explanation for the latter may be the fixed rate at which L-Phe was infused in our study, providing a weaker, but more constant, stimulus over 90 minutes. We are not aware of studies that have evaluated the course of gastric emptying of L-Phe over time, however Carney and colleagues ${ }^{26}$ reported that while oral ingestion of $\mathrm{L}-\operatorname{Trp}(\sim 3 \mathrm{~g}$ as isotonic aqueous solution) markedly slowed gastric emptying (as measured scintigraphically), compared with control (isotonic saline), more than $10 \%$ of the solution (ie, $>1.2 \mathrm{kcal}$ ) was emptied within the first 15 minutes. This relatively large initial rate of emptying would be anticipated to cause substantial stimulation of small intestinal receptors, and this is very likely to also be the case with oral L-Phe, leading to substantial CCK release. That the latter effect was much less pronounced in our ID study, is likely to be attributable to the lower infusion rate. In addition, orosensory stimulation ${ }^{27}$ and gastric distension ${ }^{28}$ may contribute to $\mathrm{CCK}$ release in response to oral L-Phe.

There was no increase in plasma CCK in response to L-Gln, and we are unaware of any other studies in humans that have eval- uated the effect of L-Gln as a CCK secretagogue. In contrast, oral and ID L-Gln (although administered in much larger doses of 15-30 g) elevated plasma glucagon-like peptide-1 (GLP-1) concentrations, in healthy, obese, and type 2 diabetic subjects. ${ }^{19,29,30}$ Our observations suggest that the effect of amino acids on CCK secretion (at loads of up to $10 \mathrm{~g}$ ) depends on the chemical characteristics of the amino acid. We have demonstrated recently that also L-Trp potently stimulates CCK secretion, ${ }^{16}$ thus, aromatic amino acids appear to be potent CCK secretagogues. This is in line with earlier studies showing that aromatic amino acids modulate upper GI function including biliopancreatic secretion, upper intestinal motility and gastrin and gastric acid secretion. ${ }^{18,31-36}$ Whether the different secretory responses are related to different amino acids transport mechanisms or luminal amino acids receptors, however, requires further research.

We also evaluated the effect of L-Phe and L-Gln on APD motility. In previous studies, ID ( $\sim 0.4$ g over 20 minutes $)$ and oral ( $\sim 3 \mathrm{~g}$ ) doses of L-Trp stimulated pyloric motility, reduced duodenal motility ${ }^{17}$ and slowed gastric emptying ${ }^{26}$ in humans. Our own recent study with L-Trp, infused ID at $0.15 \mathrm{kcal} / \mathrm{min}$ over 90 minutes (total load: $3.3 \mathrm{~g}$ ), confirmed these findings and also demonstrated a relationship between both, tonic and phasic, pyloric pressures with plasma CCK. ${ }^{16}$ We can only speculate on possible reasons for the lack of a relationship between plasma $\mathrm{CCK}$ and pyloric pressures in study A, however the more moderate increase in plasma CCK during infusion of L-Phe is likely to be one explanation. This may also explain the overall lack of L-Phe on tonic pyloric pressures. We found, however, a marked reduction in antral pressure waves during infusion of L-Phe, which correlated well with increases in plasma CCK, suggesting that the amount of CCK released was sufficient to significantly suppress antral motility. A direct comparison of the effects of L-Phe and L-Gln on antral motility across both studies (A and B) showed, however, no significant difference, possibly because of the small number of subjects included, although we identified a significant difference between L-Phe and L-Gln on CCK secretion. A comparison of the magnitude of the effects of $\mathrm{L}-\mathrm{Phe}$ on APD motility and CCK secretion with the effects seen in response to ID protein, glucose, fat or free fatty acids in our previous studies with similar experimental designs reveals that the APD and CCK responses to L-Phe are rather small.,37-39 However, it needs to be recognised that while free fatty acids were administered at comparable loads of $0.4 \mathrm{kcal} / \mathrm{min},{ }^{39}$ protein, carbohydrate and fat were administered in much higher caloric loads of up to $4 \mathrm{kcal} / \mathrm{min}$. 33,37 
We have recently identified an important role of phasic pyloric pressures and plasma CCK as independent determinants of energy intake in response to ID lipid and carbohydrate infusions. ${ }^{40}$ Although we do not relate the present data to effects on ad libitum eating, our findings contribute to a better understanding of the mechanisms underpinning the pronounced satiating capacity of high-protein diets. The stimulation of CCK and modulation of antral and phasic pyloric motility by L-Phe, like L-Trp, are likely to contribute to protein-induced satiation. Thus, the roles of dietary amino acids and proteins in the regulation of upper GI functions and energy intake warrant much further research.

We used an ID infusion paradigm to administer L-Phe and L-Glu, thus our study has a number of limitations that require consideration; while ID infusion (1) avoids potentially confounding factors, such as the substantial interindividual variations in gastric emptying, it is unable to mimic normal gastric emptying with initial periods of rapid emptying and exponential declines over time as well as pulsatile movements, and (2) allows direct stimulation of small intestinal nutrient receptors, bypassing the stomach and thus, not initiating gastric signals (eg, distension) that may modulate upper GI function.

In conclusion, acute ID administration of L-Phe, but not L-Gln, in a dose of $0.45 \mathrm{kcal} / \mathrm{min}$, suppressed antral pressures, stimulated phasic pyloric pressures, and increased plasma CCK, in a dose-dependent manner in healthy men, indicating that amino acids vary in their effects. Our observations have important implications for an improved understanding of the contributions of dietary nutrients, particularly amino acids, to the regulation of GI functions, and much further research is required to unravel the role of the different amino acids in the regulation of these functions and the relationships with the marked eating-inhibitory effect of high-protein diets.

\section{Acknowledgements}

We thank Tara Fatehi and Penelope Fitzgerald for their assistance on study days, Scott Standfield for the analysis of plasma samples for cholecystokinin, and Kylie Lange for statistical support.

\section{References}

1. Weigle DS, Breen PA, Matthys CC, et al. A high-protein diet induces sustained reductions in appetite, ad libitum caloric intake, and body weight despite compensatory changes in diurnal plasma leptin and ghrelin concentrations. Am J Clin Nutr 2005;82:41-48.
2. Brennan IM, Luscombe-Marsh ND, Seimon RV, et al. Effects of fat, protein and carbohydrate, and protein load, on appetite, plasma cholecystokinin, peptide YY and ghrelin, and energy intake in lean and obese men. Am J Physiol Gastrointest Liver Physiol 2012;303: G129-G140.

3. Ryan AT, Feinle-Bisset C, Kallas A, et al. Intraduodenal protein modulates antropyloroduodenal motility, hormone release, glycemia, appetite, and energy intake in lean men. Am J Clin Nutr 2012;96: 474-482.

4. Ma J, Stevens JE, Cukier K, et al. Effects of a protein preload on gastric emptying, glycemia, and gut hormones after a carbohydrate meal in diet-controlled type 2 diabetes. Diabetes Care 2009;32:16001602.

5. Tessari $\mathrm{P}$, Kiwanuka $\mathrm{E}$, Cristini $\mathrm{M}$, et al. Slow versus fast proteins in the stimulation of beta-cell response and the activation of the entero-insular axis in type 2 diabetes. Diabetes Metab Res Rev 2007; 23:378-385.

6. Fraser R, Fone D, Horowitz M, Dent J. Cholecystokinin octapeptide stimulates phasic and tonic pyloric motility in healthy humans. Gut 1993;34:33-37.

7. Schwizer W, Borovicka J, Kunz P, et al. Role of cholecystokinin in the regulation of liquid gastric emptying and gastric motility in humans: studies with the CCK antagonist loxiglumide. Gut 1997;41: 500-504.

8. Fried M, Erlacher U, Schwizer W, et al. Role of cholecystokinin in the regulation of gastric emptying and pancreatic enzyme secretion in humans. Studies with the cholecystokinin-receptor antagonist loxiglumide. Gastroenterology 1991;101:503-511.

9. Beglinger C. Effect of cholecystokinin on gastric motility in humans. Ann N Y Acad Sci 1994;713:219-225.

10. Beglinger S, Drewe J, Schirra J, Göke B, D'Amato M, Beglinger C. Role of fat hydrolysis in regulating glucagon-like Peptide-1 secretion. J Clin Endocrinol Metab 2010;95:879-886.

11. Feinle C, O'Donovan D, Doran S, et al. Effects of fat digestion on appetite, APD motility, and gut hormones in response to duodenal fat infusion in humans. Am J Physiol Gastrointest Liver Physiol 2003;284:G798-G807.

12. Little TJ, Russo A, Meyer JH, et al. Free fatty acids have more potent effects on gastric emptying, gut hormones, and appetite than triacylglycerides. Gastroenterology 2007;133:1124-1131.

13. Matzinger D, Degen L, Drewe J, et al. The role of long chain fatty acids in regulating food intake and cholecystokinin release in humans. Gut 2000;46:688-693.

14. Feltrin KL, Little TJ, Meyer JH, et al. Effects of intraduodenal fatty acids on appetite, antropyloroduodenal motility, and plasma CCK and GLP-1 in humans vary with their chain length. Am J Physiol Regul Integr Comp Physiol 2004;287:R524-R533.

15. Thimister PW, Hopman WP, Sloots CE, et al. Role of intraduodenal proteases in plasma cholecystokinin and pancreaticobiliary responses to protein and amino acids. Gastroenterology 1996;110: 567-575.

16. Steinert RE, Luscombe-Marsh ND, Little TJ, et al. Effects of intraduodenal infusion of L-tryptophan on ad libitum eating, antropyloroduodenal motility, glycemia, insulinemia and gut peptide secretion in healthy men. J Clin Endocrinol Metab 2014;99:3275-3284.

17. Edelbroek M, Sun WM, Horowitz M, Dent J, Smout A, 
Akkermans L. Stereospecific effects of intraduodenal tryptophan on pyloric and duodenal motility in humans. Scand J Gastroenterol 1994;29:1088-1095.

18. Ballinger AB, Clark ML. L-phenylalanine releases cholecystokinin $(\mathrm{CCK})$ and is associated with reduced food intake in humans: evidence for a physiological role of CCK in control of eating. Metabolism 1994;43:735-738.

19. Chang J, Wu T, Greenfield JR, Samocha-Bonet D, Horowitz M, Rayner CK. Effects of intraduodenal glutamine on incretin hormone and insulin release, the glycemic response to an intraduodenal glucose infusion, and antropyloroduodenal motility in health and type 2 diabetes. Diabetes Care 2013;36:2262-2265.

20. Heddle R, Dent J, Toouli J, Read NW. Topography and measurement of pyloric pressure waves and tone in humans. Am J Physiol 1988;255(4 Pt 1):G490-G497.

21. Santangelo A, Peracchi M, Conte D, Fraquelli M, Porrini M. Physical state of meal affects gastric emptying, cholecystokinin release and satiety. Br J Nutr 1998;80:521-527.

22. Samsom M, Smout AJ, Hebbard G, et al. A novel portable perfused manometric system for recording of small intestinal motility. Neurogastroenterol Motil 1998;10:139-148.

23. Samsom M, Jebbink RJ, Akkermans LM, van Berge-Henegouwen GP, Smout AJ. Abnormalities of antroduodenal motility in type I diabetes. Diabetes Care 1996;19:21-27.

24. Camilleri M, Malagelada JR. Abnormal intestinal motility in diabetics with the gastroparesis syndrome. Eur J Clin Invest 1984;14: 420-427.

25. Bland JM, Altman DG. Calculating correlation coefficients with repeated observations: part 1--correlation within subjects. BMJ 1995; 310:446

26. Carney BI, Jones KL, Horowitz M, Sun WM, Hebbard G, Edelbroek MA. Stereospecific effects of tryptophan on gastric emptying and hunger in humans. J Gastroenterol Hepatol 1994;9:557563.

27. Depoortere I. Taste receptors of the gut: emerging roles in health and disease. Gut 2014;63:179-190.

28. Koop I, Ruppert-Seipp G, Koop H, Schafmayer A, Arnold R. Cholecystokinin release by gastric distension--an atropine-sensitive mechanism. Digestion 1990;46:220-227.

29. Samocha-Bonet D, Wong O, Synnott EL, et al. Glutamine reduces postprandial glycemia and augments the glucagon-like peptide-1 re- sponse in type 2 diabetes patients. J Nutr 2011;141:1233-1238.

30. Greenfield JR, Farooqi IS, Keogh JM, et al. Oral glutamine increases circulating glucagon-like peptide 1 , glucagon, and insulin concentrations in lean, obese, and type 2 diabetic subjects. Am J Clin Nutr 2009;89:106-113.

31. Bull JS, Grundy D, Scratcherd T. The effect of intraluminal tryptophan and phenylalanine on small intestinal motility in the conscious dog. J Physiol 1985;367:353-362.

32. Colombel JF, Sutton A, Chayvialle JA, Modigliani R. Cholecystokinin release and biliopancreatic secretion in response to selective perfusion of the duodenal loop with aminoacids in man. Gut 1988; 29:1158-1166.

33. Konturek SJ, Radecki T, Thor P, Dembinski A. Release of cholecystokinin by amino acids. Proc Soc Exp Biol Med 1973;143: 305-309.

34. Strunz UT, Walsh JH, Grossman MI. Stimulation of gastrin release in dogs by individual amino acids. Proc Soc Exp Biol Med 1978; $157: 440-441$.

35. McArthur KE, Isenberg JI, Hogan DL, Dreier SJ. Intravenous infusion of L-isomers of phenylalanine and tryptophan stimulate gastric acid secretion at physiologic plasma concentrations in normal subjects and after parietal cell vagotomy. J Clin Invest 1983;71:12541262.

36. Meyer JH, Grossman MI. Comparison of D- and L-phenylalanine as pancreatic stimulants. Am J Physiol 1972;222:1058-1063.

37. Pilichiewicz AN, Chaikomin R, Brennan IM, et al. Load-dependent effects of duodenal glucose on glycemia, gastrointestinal hormones, antropyloroduodenal motility, and energy intake in healthy men. Am J Physiol Endocrinol Metab 2007;293:E743-E753.

38. Pilichiewicz AN, Papadopoulos P, Brennan IM, et al. Load-dependent effects of duodenal lipid on antropyloroduodenal motility, plasma CCK and PYY, and energy intake in healthy men. Am J Physiol Regul Integr Comp Physiol 2007;293:R2170-R2178.

39. Feltrin KL, Little TJ, Meyer JH, et al. Comparative effects of intraduodenal infusions of lauric and oleic acids on antropyloroduodenal motility, plasma cholecystokinin and peptide YY, appetite, and energy intake in healthy men. Am J Clin Nutr 2008;87:1181-1187.

40. Seimon RV, Lange K, Little TJ, et al. Pooled-data analysis identifies pyloric pressures and plasma cholecystokinin concentrations as major determinants of acute energy intake in healthy, lean men. Am J Clin Nutr 2010;92:61-68. 